\title{
Self-Efficacy and Self-Regulated Learning Strategies for English Language Learners: Comparison between Chinese and German College Students
}

\author{
Chuang Wang ${ }^{1}$, Götz Schwab ${ }^{2}$, Pete Fenn ${ }^{2} \&$ Mei Chang ${ }^{3}$ \\ ${ }^{1}$ University of North Carolina at Charlotte, Charlotte, North Carolina, USA \\ ${ }^{2}$ Pädagogische Hochschule Ludwigsburg, Ludwigsburg, Germany \\ ${ }^{3}$ University of North Texas, Denton, Texas, USA \\ Correspondence: Chuang Wang, College of Education, University of North Carolina at Charlotte, Charlotte, NC, \\ USA. Tel: 1-704-687-8708. E-mail: cwang15@uncc.edu
}

Received: December 11, 2012 Accepted: January 18, $2013 \quad$ Online Published: April 11, 2013

doi:10.5539/jedp.v3n1p173 URL: http://dx.doi.org/10.5539/jedp.v3n1p173

\begin{abstract}
Two hundred Chinese and 160 German college students completed two surveys about their self-efficacy beliefs and self-regulated learning (SRL) strategies learning English in China and Germany. All participants took an English language test to measure their English proficiency. Cronbach's alpha was used to check the internal consistency of the surveys, and confirmatory factor analysis was employed for the construct validity. Factorial invariance of the self-efficacy survey was tested between Chinese and German students. Both surveys turned out to be reliable and valid with satisfactory goodness-of-fit indices. The self-efficacy survey was found to have the same latent structure between Chinese and German students. The SRL strategy survey, however, was found to have a different latent structure. Mean differences between Chinese and German students were compared with multivariate analysis of variance, and relationships between self-efficacy, SRL strategies, and English proficiency were examined with structural equation modeling. Chinese students reported a lower level of self-efficacy beliefs but their English proficiency was not significantly different in comparison to German students. Their use of SRL strategies was not significantly different, either. Statistically significant relationships were noted between self-efficacy, use of SRL strategies, and English language test scores. Female students reported higher levels of self-efficacy beliefs but gained lower scores on the English language test in both countries. Implications of the results are discussed for English language instruction in both countries. Future studies are recommended to use the same English language test in two countries and to use a balanced sample between male and female students.
\end{abstract}

Keywords: self-efficacy, self-regulated learning strategies, English language learner, college students

\section{Introduction}

English language is spoken in 188 countries and is the official language of 83 countries. As a result, English is considered "world language" and is used as an official language for all international conferences. College students in most non-English speaking countries are required to take English language courses to meet the need of internationalization and communications with people outside of the country. In China, for example, most students start to learn English in elementary schools, and college students are required to take four hours of English courses each week during the first two years and have to pass a national-level standardized test (College English Test Band Four) in order to receive their diplomas in most universities. English is also a major subject test for the admission to graduate schools in China. In Germany, English is the prevailing foreign language taught at secondary schools and is also compulsory in almost all elementary schools across the country. Although more and more study programs are beginning to design courses in English as a lingua franca, English is not the official academic language at university level. Although Chinese and German students are similar in the English language learning context, the cultural and linguistic differences make it important to examine similarities and differences in their process of learning English. This paper focuses on Chinese and German college students' self-efficacy beliefs and their use of self-regulated learning (SRL) strategies in learning English as a foreign language. 


\subsection{Self-Efficacy, Self-Regulation, and Academic Achievement}

Self-efficacy is defined as "beliefs in one's capabilities to organize and execute courses of action required to produce given attainments" (Bandura, 1997, p. 3) and is part of the self-regulation process. The process of self-regulation consists of three phases: forethought, performance, and self-reflection (Zimmerman, 2000). The forethought phase includes processes and beliefs that precede efforts to learn, such as motivation, self-efficacy, goal-setting, and planning. Among these concepts, self-efficacy is most often misinterpreted and often confused with similar constructs like self-concept, self-esteem, and self-confidence.

Some scholars viewed self-concept as a global construct and operationally defined it as a composite score from multiple scales such as behavior, academic status, physical appearance, anxiety, happiness, and satisfaction (Byrne, 1996; Piers \& Harris, 1964). This practice, however, was criticized for its failure to distinguish activities in different domains (e.g., Bong, 2006; Marsh, 1992; Marsh, Byrne, \& Shavelson, 1988). These scholars claim that self-concept consists of competence judgments coupled with evaluative reactions (e.g., Bong \& Clark, 1999; Pajares, 1996; Schunk, 1991). Therefore, the common factor between self-concept and self-efficacy is perceived competence. Self-esteem is a general sense of worth and reflects how one feels about one's achievement in a specific domain (Byrne, 1996; Damon \& Hart, 1982).

The performance phase refers to processes that students focus on to complete a task and optimize their performance. Examples of these processes include attention control, keeping records, and monitoring. The self-reflection phase refers to processes associated with self-observation, such as self-evaluation. During this phase, students compare information about their performance with a standard or goal and ascribe causal meaning to the results. They make a judgment about whether an unsatisfactory result is due to their limited capability or insufficient effort.

Self-regulation and self-efficacy are related constructs in which self-efficacy is perceived to be a subcomponent of self-regulation. Self-regulation reflects any effort individuals make to modify their responses through inhibiting impulses and substituting them with different approaches that lead to desirable outcomes; thus, individuals with strong self-regulation tend to be highly self-efficacious (Luszczynska, Gutierrez-Dona, \& Schwarzer, 2005). Not all strategies are self-regulated learning (SRL) strategies. Pintrich (2004) proposed four important assumptions for SRL strategies: (a) learners are actively constructing meaning, setting goals, and choosing strategies; (b) learners have the potential to control the direction of their learning; (c) the strategies are goal-oriented rather than random; and (d) the strategies mediate the relationship between personal and contextual characteristics and achievement or performance.

The relationships between self-efficacy, SRL strategies, and academic achievement have been studied extensively in the domains of first language English writing and mathematics education (e.g., Boekaerts \& Cascallar, 2006; Pajares \& Valiante, 2002; Pape \& Wang, 2003; Zimmerman \& Cleary, 2006; Zimmerman \& Martinez-Pons, 1990). Studies of these relationships in the context of learning English as a foreign language, however, are limited (Huang, Lloyd, \& Mikulecky, 1999). Therefore, it is crucial to study students' self-efficacy beliefs and SRL strategies in the context of foreign language learning process. Self-efficacy is malleable and content specific (Klassen, 2004). These beliefs and strategies vary as a function of tasks and contexts (Bong, 2002; Pintrich \& Schunk, 1996). Studies about gender differences in the development of self-efficacy beliefs suggest that social persuasions and vicarious experiences are critical to women's self-efficacy beliefs whereas mastery experience is critical to men's self-efficacy (Zeldin, Britner, \& Pajares, 2008). Gender differences in self-efficacy beliefs in mathematics were no longer noticed after receiving proper performance feedback for middle school students (Schunk \& Lilly, 1984).

\subsection{Self-Efficacy and Self-Regulation across Cultures}

In cross-cultural studies, lower self-efficacy for self-regulation was found in Singapore students than in Canadian students (Klassen et al., 2009). Similarly, Al-Harthi (2010) reported that Arab students' perceived self-regulation was lower than that of American counterparts, and they attributed the difference to culture effect (future orientation).

While it is suggested that self-efficacy is a universal and one-dimensional construct, differences in perceived levels of self-efficacy were found between countries (Scholz et al., 2002). Studies examining self-efficacy across nations indicated that Asian students reported lower self-efficacy beliefs despite outperforming their counterparts in academic achievement (Scholz et al., 2002; Yan \& Gaier, 1994). Specifically, several cross-cultural studies about self-efficacy beliefs claimed Chinese students were more likely to report lower levels of self-efficacy beliefs when compared to European and American students (Earley, 1999; Eaton \& Dembo, 1997; Salili et al., 2001; Scholz et al., 2002; Schwarzer \& Born, 1997). When comparing Asian nation groups, differences were 
found among Asian students in different countries. Students in Hong Kong and Japan reported lower self-efficacy scores than did students from Indonesia, with students from Japan reporting the lowest scores (Schwarzer, Born, Iwawaki, Lee, Saito, \& Yue, 1997). An examination of general self-efficacy across German, Poland, and South Korea also suggested cross-cultural differences in which the Korean sample reported lower self-efficacy scores than did the German and Poland (Luszczynska, Scholz, \& Schwarzer, 2005) samples. Gender differences were also found in cross-cultural studies; in particular, significant gender differences emerged in the Chinese sample in which women obtained lower self-efficacy scores than men (Scholz et al., 2002; Schwarzer, BaBler, Kwiatek, Schroder, \& Zhang, 1997).

Researchers have postulated that attributions may account for differences in perceived self-efficacy in that effort and hard work are more highly valued than ability in collective cultures; as a result, self-efficacy tends to be reported lower in collective cultures than in individualistic cultures (Eaton \& Dembo, 1997). Moreover, differences in the perceived self-efficacy scores across nations may reflect variations in linguistic and cultural backgrounds, which might moderate the associations between self-efficacy and related constructs (e.g., self-regulation) (Eaton \& Dembo, 1997; Salili et al., 2001). Therefore, investigating linguistic effects on students' self-efficacy in relation to self-regulated learning strategies is warranted.

\subsection{Measurement of Self-Efficacy and Self-Regulation}

Motivated Strategies for Learning Questionnaire (MSLQ), published in 1990, was developed by a group of scholars at the University of Michigan. The psychometric properties of MSLQ, which consists of 6 motivation subscales and 9 learning strategy subscales with 81 items, were examined (e.g., Barker \& Olsen, 1995; Pintrich, Smith, Garcia, \& McKeachie, 1993; Sachs, Law, Chan, \& Rao, 2001). These 15 subscales can be used together or separately. One of the subscales is "Self-Efficacy for Learning and Performance," which is composed of 8 items. These eight items measure student beliefs of how well they can succeed in an undergraduate course, but cannot measure the specifics of language learning as self-efficacy needs to be tailored to the particular domain of interest (Bandura, 2006). Other subscales of MSLQ are about goal orientation, task value, expectancy, cognitive and metacognitive strategies, and resource management strategies, none of which was designed for English language learners.

In the field of teaching English as a second or foreign language, Oxford (1990) developed the Strategy Inventory for Language Learning (SILL) to measure three direct language learning strategies (cognitive, memory, and compensatory) and three indirect language learning strategies (metacognitive, affective, and social strategies). The reliability and validity of information provided by SILL have been examined (Green \& Oxford, 1995; Hsiao \& Oxford, 2002). SILL has been used in a variety of languages and countries (Oxford, 1996; Nisbet, Tindall, \& Arroyo, 2005; Oxford \& Burry-Stock, 1995). The strategies included in SILL, however, focused heavily on language acquisition. Although some of the strategies in SILL could be considered SRL strategies, SILL does not reflect the three phases of self-regulation defined by Zimmerman (2000) or the four assumptions of self-regulation articulated by Pintrich (2004). Incorporating self-regulation into the field of language acquisition, Oxford (2011) developed the $S^{2} R$ model of language learning, which is a dynamic interaction of strategies (cognitive, sociocultural-interactive, and affective) and metastrategies (metacognitive, meta-sociocultural-interactive, and meta-affective). Following Pintrich's (2004) theoretical framework of self-regulation, a group of scholars suggest that measurement of self-regulation should be dynamic and should identify self-regulation in action (Ainley \& Patrick, 2006; Turner, 2006).

The literature review suggests a need to investigate the relationships between self-efficacy, SRL strategies, and achievement in learning English as a foreign language. As a result, the purposes of this study are three folds: (a) to examine the psychometric properties of the self-efficacy survey with Chinese and German students; (b) to compare the self-efficacy, SRL strategies, and achievement of Chinese and German college students; and (c) to see how the relationships between these constructs differ between Chinese and German college students.

\section{Methods}

\subsection{Procedure and Participants}

Participants were recruited through university professors at one university in Germany and another university in China, both located in mid-size cities. The data for this study were collected among prospective foreign language teachers studying English either as their major or minor subject in an undergraduate teacher training setting.

After removing students with incomplete responses, data from 200 students in the Chinese university and 160 students in the German university were used. Of the 200 students in China, $58(29 \%)$ were male and $142(71 \%)$ were female. Of the 160 students in Germany, 31 (19\%) were male and $129(81 \%)$ were female. All Chinese 
students were in the second year of the college whereas most (92\%) of the German students were either in the first year $(65 \%)$ or in the second year $(27 \%)$. Chinese participants $(M=20.03, S D=1.11)$ were relatively younger than German participants $(M=21.69, S D=2.80)$. This difference was statistically significantly different from zero, $t(357)=7.66, p<.001$, with a medium effect size (Cohen's $d=0.78$ ).

\subsection{Instruments}

\subsubsection{Self-Efficacy Survey}

The Questionnaire of English Self-Efficacy (QESE) consists of 32 items (Appendix A). Each item asks students to make judgments about their capabilities to accomplish certain tasks using English in listening, speaking, reading, and writing contexts. An examination of the rating scale structure with Item Response Theory (IRT) showed that participants reliably distinguished response categories, and the item hierarchy was consistent with the expected item order (Wang, Kim, Bong, \& Ahn, in press). Previous studies with Chinese and Korean college students (Wang et al., in press) confirmed the four distinct factors and a second-order common factor. The common factor is named as English Self-efficacy whereas the four factors are named as Listening Efficacy (Items 1, 3, 9, 10, 15, 22, 24, and 27), Speaking Efficacy (Items 4, 6, 8, 17, 19, 20, 23, and 30), Reading Efficacy (Items 2, 12, 16, 21, 25, 26, 29, and 32), and Writing Efficacy (Items 5, 7, 11, 13, 14, 18, 28, and 31). The internal consistency (Cronbach's alpha) was .96 , test-retest reliability was .82 , the concurrent validity was .55 , and the predictive validity was .41 (see Wang, Wang, \& $\mathrm{Li}, 2007$ for detailed reliability and validity information). Students were asked to rate their capabilities on a 7-point Likert scale from 1 (I cannot do it at all) to 7 (I can do it very well).

\subsubsection{Self-Regulated Learning Strategy Survey}

The Questionnaire of English Self-Regulated Learning Strategies (QESRLS) includes 67 items (Appendix B). Each item describes an SRL strategy commonly used in studying English and falls into one of the 12 categories: Self-Evaluation (Items 8, 30, 58, and 65), Organizing and Transforming (Items 2, 13, 16, 18, 21, 26, 32, 34, 37, $38,40,44,45,50,57,60,63$, and 64), Rehearsing and Memorizing (Items 14, 22, 24, 28, and 43), Seeking Social Assistance (Items 6, 12, and 19), Persistence (Items 5, 9, and 20), Seeking Opportunities (Items 23, 29, 39, 46, 48, 52, 54, and 66), Taking Records (Items 1 and 4), Self-Consequence (Items 15 and 53), Goal-Setting (Items 7, 10, and 11), Reviewing Records (Items 3 and 51), Use of Native Language (Items 33, 41, 47, 49, 55, and 67), and Interpretive Guessing (Items 25, 27, 31, 35, and 59). The context ranges from cognitive components to generally accepted English learning strategies, including strategies such as goal-setting, making adjustment, and seeking social assistance. Internal consistency (Cronbach's alpha) was .96, test-retest reliability was .88, concurrent validity was .62, and predictive validity was .57 (see Wang et al., 2007 for details). Students were asked to respond by circling one of the four choices: $0=$ "I never use it," $1=$ "I seldom use it," $2=$ "I sometimes use it," and 3 = "I often use it."

\subsubsection{English Language Test}

All participants completed an English language test after taking the surveys. The English language test is English grammar based in both countries and covered content areas in tense and semantics. The English language test in Germany was consisted of two parts. In Part I, verbs as infinitives were given in brackets, and students were asked to put the verbs in correct tense and form. In Part II, students can choose one of the options. In one option, students were given two sentences, each of which reflects a single grammatical difference. Students were asked to describe the semantic differences and explain how tense and semantic rules caused the differences. In another option, students were given sentences with or without grammatical mistakes with respect to tense and semantics. Students had to identify the mistakes and correct them. The total score of the English test in Germany is 40 (20 points for each part). The English language test in China was also consisted of three parts. Part I is in multiple choice format, and students were expected to choose the best word in tense and form to fill in a sentence. Part II is reading comprehension, where students were given four texts that they had to read and answer questions about the information in the texts. Part III is translation, where students were given sentences in Chinese and had to translate them into English. This part was graded by the number of grammatical and semantic mistakes students made in translation. The total score of the English test in China was 100. The English language test score in Germany was converted to percentage afterwards for the sake of comparison to that in China.

\subsection{Data Analytical Procedure}

First, single group CFA was conducted for each group to assess the overall model fit of the self-efficacy survey using the $\chi^{2}$ statistic, Standardized Root Mean Square Residual (SRMR), Root Mean Square Error of Approximation (RMSEA), Nonnormed Fit Index (NNFI), and Comparative Fit Index (CFI). The 2-index 
presentation strategy (i.e., SRMR coupled with another index) suggested by Hu and Bentler (1999) was not used because they were based on very restrictive assumptions (Marsh, Hau, \& Wen, 2004) and cautions to use this strategy was raised by Fan and Sivo (2005). Following our previous research (Wang et al., in press), a two-level four-subconstruct measurement model was chosen for the CFAs. The first level was self-efficacy, and the second level consisted of the four subconstructs: listening, speaking, reading, and writing.

Second, multigroup CFA was conducted to test the factorial invariance across the groups with LISREL 8.8 (Jöreskog \& Sörbom, 2006). Different levels of factorial invariance between the student groups were tested through the following three steps: (a) all parameters were freely estimated (Model 1, baseline model); (b) the factor loadings were constrained to be equal for each pair of the four dimensions of self-efficacy across the groups (Model 2); and (c) factor loadings and error variances were constrained to be equal for each pair of the four dimensions of self-efficacy across the groups (Model 3). Significant changes in $\chi^{2}$ and changes in CFI values of .01 or above were used to flag significant differences when testing the models (Cheung \& Rensvold, 2002).

Third, one-way analysis of variance (ANOVA) was employed to examine differences in the mean self-report of self-efficacy across the two groups of students. Multivariate analysis of variance (MANOVA) was used to see if the groups differ on the combination of the four subconstructs of self-efficacy. Group differences in self-efficacy, self-regulation, and achievement in learning English (measured by the English language test) were also examined with MANOVA by controlling gender differences.

Fourth, structural equation modeling was employed to examine the relationships between self-efficacy beliefs, use of SRL strategies, and English language test scores with consideration of the measurement error.

Finally, participants were put into two groups by their responses in the survey (QESRLS) to the question about if they read a passage first before answering questions about the passage or read the questions first then find the answer in the passage. The variable created to represent these two groups is a dummy variable "passage" with " 0 " standing for reading the passage first and " 1 " standing for reading the questions first. Median score of their responses was used to split them into two groups. Three-way MANOVA was used to see if students differ on the combination of their English language test scores and self-efficacy beliefs with independent variables of country of origin, gender, and passage.

\section{Results}

CFAs were conducted separately for each group to assess the fit of the four-factor model of QESE to the data. Results indicated that the two-level four-construct model was not rejected, suggesting that the model adequately represented the factorial structure of self-efficacy $(\mathrm{NNFI}=.96, \mathrm{CFI}=.97, \mathrm{RMSEA}=.10$, and SRMR $=.08$ for the Chinese students; NNFI $=.97, \mathrm{CFI}=.97$, RMSEA $=.08$, and SRMR $=.07$ for the German students). See Table 1 for detailed information about the goodness of fit indices and Figures 1 and 2 for the latent and item structure of QESE.

Table 1. Model fit indices for self-efficacy survey

\begin{tabular}{lcccccccccccc}
\hline & & df & Ratio & GFI & AGFI & NFI & NNFI & CFI & SRMA & RMSEA & 90\%LL & 90UL \\
\hline China & 1357.92 & 460 & 2.95 & .70 & .66 & .95 & .96 & .97 & .08 & .099 & .093 & .110 \\
Germany & 944.26 & 460 & 2.05 & .73 & .69 & .94 & .97 & .97 & .07 & .081 & .074 & .089 \\
\hline
\end{tabular}

Note. GFI=Goodness of Fit, AGFI=Adjusted Goodness of Fit, NFI=Normed Fit Index, NNFI=Non-Normed Fit Index, CFI=Comparative Fit Index, SRMR=Standardized Root Mean Residual, RMSEA=Root Mean Square Error of Approximation. 


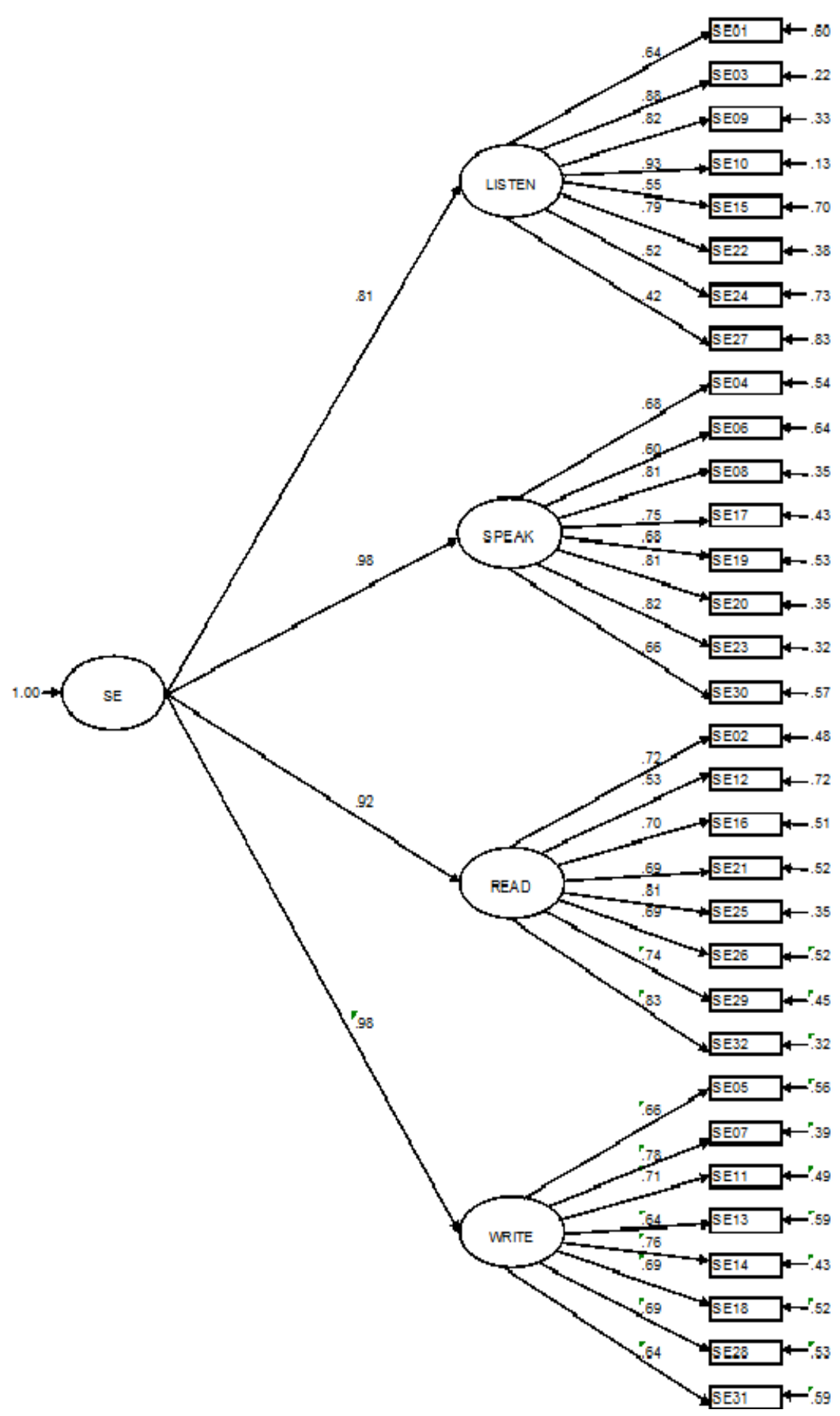

Figure 1. Structure of self-efficacy survey (German students) 


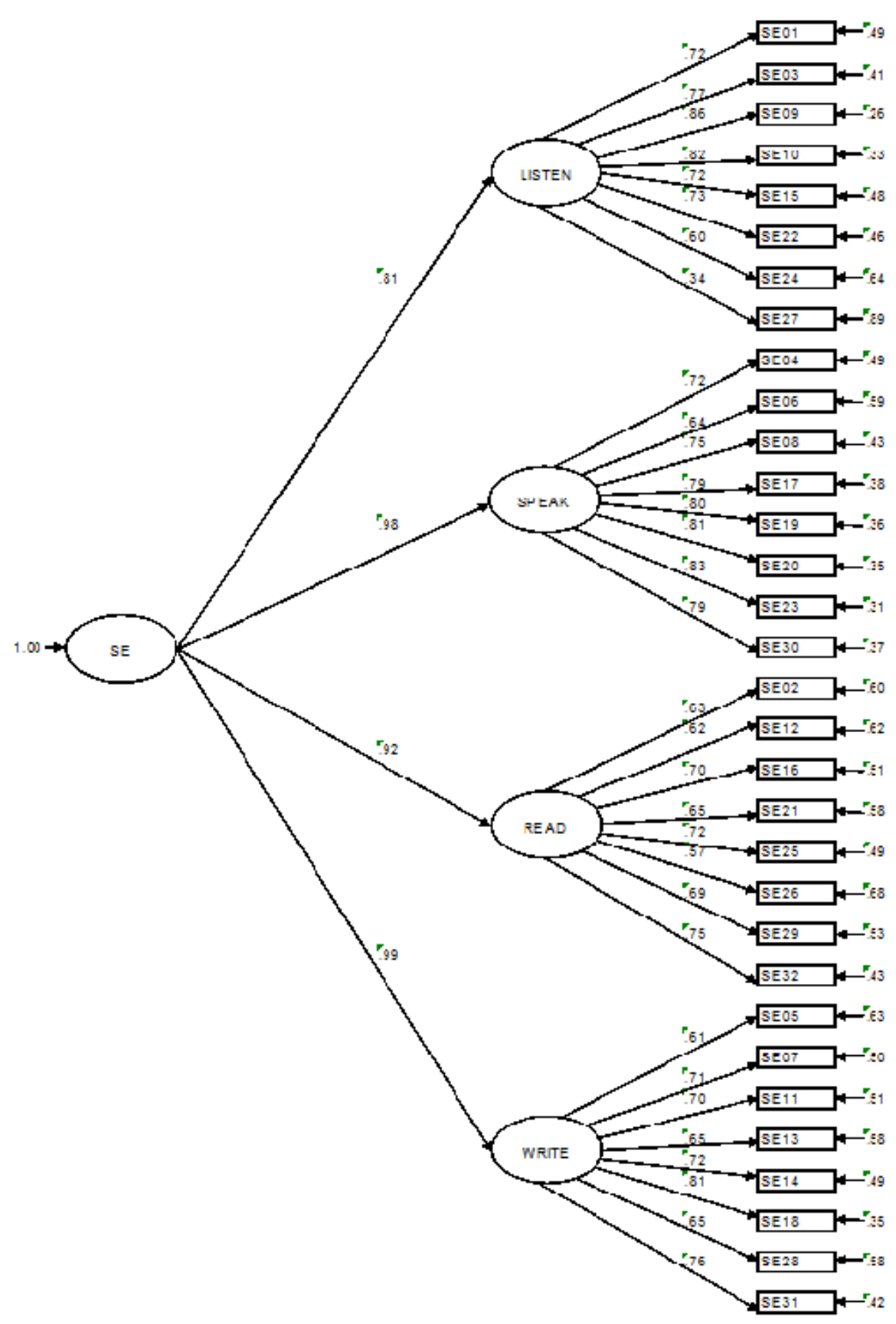

Figure 2. Structure of self-efficacy survey (Chinese students)

In testing factorial invariance, Model 1 was used as the baseline model with which the more constrained models (i.e., Model 2 and Model 3) were compared. The results of the invariance tests are presented in Table 2. 
Table 2. Test of invariance by group and model

\begin{tabular}{llllllll}
\hline Model & $d f$ & $\chi 2$ & $\Delta d f$ & $\Delta \chi 2$ & CFI & $\Delta$ CFI & SRMR \\
\hline Model 1 & 945 & 2593.76 & - & - & .96 & - & .09 \\
Model 2 & 948 & 2593.76 & 3 & 0.00 & .96 & .00 & .09 \\
Model 3 & 984 & 2670.20 & 36 & 76.44 & .96 & .00 & .12
\end{tabular}

Note. (1) $\mathrm{CFI}=$ comparative fit index; SRMR = standardized root mean square residual; $(2)^{*} p<.05$.

In Model 1, all fit values showed good fit of the data, suggesting that the factorial pattern of QESE was similar across Chinese and German college students. These students appeared to have a similar pattern of their self-efficacy beliefs. In Model 2, the factor loadings were imposed to be equal across the groups. The CFI difference $(\Delta \mathrm{CFI})$ between Model 1 and Model 2 was equal to zero and the SRMR fit values stayed the same from Model 1 to Model 2, suggesting that factor loadings were invariant across the groups. When both the factor loadings and error variances were imposed to be equal across the groups (Model 3), the $\Delta$ CFI was still zero but the SRMR value increased by .03, indicating that Model 3 is also acceptable. The increase of SRMR values from Model 2 to Model 3 suggested that Model 2 fit our data better than Model 3. In summary, there was not a significant difference in the error variances between Chinese and German college students, and the factor loadings were the same across the groups. These results make it possible to compare the mean constructs between the two groups of students.

\subsection{Mean Comparisons of QESE}

Table 3 displays the means and standard deviations for all QESE constructs, Cronbach's alpha for each construct, and correlation coefficients between each construct.

Table 3. Means (standard deviations) and correlation coefficients of self-efficacy

\begin{tabular}{lllllll}
\hline Group & & Self-Efficacy & Listen & Speak & Read & Write \\
\hline China & Self-Efficacy & -- & $.92^{* *}$ & $.95^{* *}$ & $.94^{* *}$ & $.95^{* *}$ \\
$(\boldsymbol{n = 2 0 0 )}$ & Listen & & -- & $.81^{* *}$ & $.84^{* *}$ & $.80^{* *}$ \\
& Speak & & -- & $.83^{* *}$ & $.90^{* *}$ \\
& Read & & & -- & $.84^{* *}$ \\
& $\boldsymbol{M}(\boldsymbol{S D})$ & $4.64(0.88)$ & $4.34(0.92)$ & $4.80(0.99)$ & $4.73(0.90)$ & $4.70(0.94)$ \\
& Alpha & .97 & .93 & .90 & .89 & .89 \\
\hline Germany & Self-Efficacy & -- & $.90^{* *}$ & $.92^{* *}$ & $.93^{* *}$ & $.92^{* *}$ \\
$(\boldsymbol{n = 1 6 0 )}$ & Listen & & -- & $.71^{* *}$ & $.84^{* *}$ & $.73^{* *}$ \\
& Speak & & & -- & $.78^{* *}$ & $.88^{* *}$ \\
& Read & & & & -- & $.78^{* *}$ \\
& $\boldsymbol{M}(\boldsymbol{S D})$ & $5.59(0.71)$ & $5.60(0.81)$ & $5.69(0.78)$ & $5.58(0.74)$ & $5.51(0.74)$ \\
& Alpha & .97 & .88 & .90 & .89 & .89 \\
\hline
\end{tabular}

One-way ANOVA indicated that German students $(M=5.59, S D=0.70)$ were more efficacious than Chinese students $(M=4.64, S D=0.88), F(1,349)=112.34, p<.001, \eta^{2}=.24$. Same results were found for each QESE subscale. In general, female students $(M=5.21, S D=0.96)$ were more efficacious than male students $(M=4.90$, $S D=0.88), F(1,349)=5.64, p=.02, \eta^{2}=.02$. Same results were found for each QESE subscale.

3.2 Mean Comparisons of QESE, QESRLS, and Achievement

Descriptive statistics and Cronbach's alpha about QESRLS and its subscales are presented in Table 4 for Chinese students and Table 5 for German students. 
Table 4. Means (standard deviations) and correlation coefficients for SRL strategies (Chinese students)

\begin{tabular}{|c|c|c|c|c|c|c|c|c|c|c|c|c|c|c|}
\hline & SEV & ORG & REH & SEK & PER & OPP & REC & $\mathrm{CON}$ & GOA & REV & LAN & GUS & $\mathrm{M}(\mathrm{SD})$ & Alpha \\
\hline SRL & $.67 * *$ & $.91^{* *}$ & $.65^{* *}$ & $.34 * *$ & $.60 * *$ & $.75^{* *}$ & $.55^{* *}$ & $.44^{* *}$ & $.71 * *$ & $.59^{* *}$ & $.29 * *$ & $.66^{* *}$ & $1.71(0.35)$ & .92 \\
\hline SEV & -- & $.57 * *$ & $.39 * *$ & $.23 * *$ & $.38 * *$ & $.38^{* *}$ & $.40 * *$ & $.29^{* *}$ & $.43 * *$ & $.44^{* *}$ & $.31 * *$ & $.50^{* *}$ & $1.91(0.61)$ & .64 \\
\hline ORG & & -- & $.58^{* *}$ & $.19^{* *}$ & $.48^{* *}$ & $.60^{* *}$ & $.47^{* *}$ & $.39^{* *}$ & $.60^{* *}$ & $.52 * *$ & $.44 * *$ & $.60^{* *}$ & $1.75(0.51)$ & .88 \\
\hline REH & & & -- & .12 & $.24 * *$ & $.44^{* *}$ & $.38 * *$ & $.23^{* *}$ & $.43^{* *}$ & $.46^{* *}$ & $.35^{* *}$ & $.34 * *$ & $1.65(0.55)$ & .62 \\
\hline SEK & & & & -- & $.26^{* *}$ & $.29 * *$ & $.20 * *$ & .13 & $.18^{* *}$ & .09 & .06 & .12 & $1.50(0.43)$ & .33 \\
\hline PER & & & & & -- & $.38 * *$ & $.36^{* *}$ & $.27^{* *}$ & $.40^{* *}$ & $.26^{* *}$ & $.23^{* *}$ & $.54 * *$ & $2.22(0.60)$ & .66 \\
\hline OPP & & & & & & -- & $.29 * *$ & $.33^{* *}$ & $.56^{* *}$ & $.35^{* *}$ & $.28^{* *}$ & $.35^{* *}$ & $1.42(0.60)$ & .83 \\
\hline REC & & & & & & & -- & $.19^{* *}$ & $.38^{* *}$ & $.42^{* *}$ & $.15^{* *}$ & $.28^{* *}$ & $1.75(0.66)$ & .32 \\
\hline CON & & & & & & & & -- & $.22 * *$ & $.17^{*}$ & $.27^{* *}$ & $.28^{* *}$ & $1.89(0.70)$ & .35 \\
\hline GOA & & & & & & & & & -- & $.39 * *$ & $.27^{* *}$ & $.41^{* *}$ & $1.69(0.70)$ & .64 \\
\hline REV & & & & & & & & & & -- & $.22 * *$ & $.32 * *$ & $1.86(0.74)$ & .51 \\
\hline LAN & & & & & & & & & & & -- & $.31^{* *}$ & $1.74(0.58)$ & .69 \\
\hline GUS & & & & & & & & & & & & -- & $2.17(0.52)$ & .65 \\
\hline
\end{tabular}

Note. $\mathrm{SRL}=$ self-regulated learning; $\mathrm{SEV}=$ self-evaluation; $\mathrm{ORG}=$ organizing and transforming; $\mathrm{REH}=$ rehearsing and memorizing; SEK = seeking social assistance; PER = persistence; OPP = seeking opportunities; $\mathrm{REC}=$ taking records; $\mathrm{CON}=$ self-consequence; $\mathrm{GOA}=$ goal-setting; $\mathrm{REV}=$ reviewing records; $\mathrm{LAN}=$ use of native language; GUS $=$ interpretive guess; $* p<.05 ; * * p<.01$.

Table 5. Means (standard deviations) and correlation coefficients for SRL strategies (German students)

\begin{tabular}{|c|c|c|c|c|c|c|c|c|c|c|c|c|c|c|}
\hline & SEV & ORG & REH & SEK & PER & OPP & REC & $\mathrm{CON}$ & GOA & REV & LAN & GUS & $\mathrm{M}(\mathrm{SD})$ & Alpha \\
\hline SRL & $.43^{* *}$ & $.74 * *$ & $.51 * *$ & $.36 * *$ & $.38 * *$ & $.65^{* *}$ & $.33 * *$ & $.26 * *$ & $.41 * *$ & $.33 * *$ & $-.16^{*}$ & $.29 * *$ & $1.68(0.23)$ & .79 \\
\hline SEV & -- & $.31 * *$ & $.16^{*}$ & .11 & $.26 * *$ & .06 & $.23 * *$ & $.24 * *$ & $.26 * *$ & $.31 * *$ & .06 & -.05 & $2.42(0.44)$ & .42 \\
\hline ORG & & -- & $.39 * *$ & .11 & $.18^{*}$ & $.25^{* *}$ & $.21 * *$ & .12 & $.44 * *$ & $.21 * *$ & $.31 * *$ & $.19^{*}$ & $1.44(0.36)$ & .70 \\
\hline REH & & & -- & $.23 * *$ & .08 & $.16^{*}$ & $.27 * *$ & .14 & $.40 * *$ & $.17^{*}$ & $.26 * *$ & .10 & $1.01(0.50)$ & .49 \\
\hline SEK & & & & -- & .08 & $.25 * *$ & $.16^{*}$ & .01 & $.16^{*}$ & $.16^{*}$ & -.14 & -.10 & $1.50(0.42)$ & .37 \\
\hline PER & & & & & -- & $.24 * *$ & .07 & .11 & .02 & .11 & -.08 & .08 & $2.50(0.43)$ & .37 \\
\hline OPP & & & & & & -- & .09 & .04 & -.11 & .04 & $-.30 * *$ & .12 & $1.63(0.59)$ & .74 \\
\hline REC & & & & & & & -- & .03 & $.22 * *$ & $.27 * *$ & .06 & -.08 & $1.86(0.54)$ & .20 \\
\hline CON & & & & & & & & -- & .13 & .12 & .06 & .14 & $1.59(0.63)$ & .12 \\
\hline
\end{tabular}




\begin{tabular}{|c|c|c|c|c|c|c|}
\hline GOA & -- & $.19 *$ & $20 * *$ & .02 & $1.31(0.61)$ & .50 \\
\hline REV & & -- & .01 & .02 & $2.58(0.40)$ & .15 \\
\hline LAN & & & -- & .04 & $1.45(0.65)$ & .75 \\
\hline GUS & & & & -- & $2.22(0.42)$ & .35 \\
\hline
\end{tabular}

Note. $\mathrm{SRL}=$ self-regulated learning; $\mathrm{SEV}=$ self-evaluation; $\mathrm{ORG}=$ organizing and transforming; $\mathrm{REH}=$ rehearsing and memorizing; SEK = seeking social assistance; $\mathrm{PER}=$ persistence; $\mathrm{OPP}=$ seeking opportunities; $\mathrm{REC}=$ taking records; $\mathrm{CON}=$ self-consequence; $\mathrm{GOA}=$ goal-setting; $\mathrm{REV}=$ reviewing records; $\mathrm{LAN}=$ use of native language; GUS $=$ interpretive guess; $* p<.05 ; * * p<.01$.

MANOVA did not identify a statistically significant interaction effect between gender and country of origin on the combination of self-efficacy beliefs, use of SRL strategies, and English language test scores, $F(3,301)=$ $0.42, p=.74, \eta^{2}=.004$. The main effects of country and gender, however, were both statistically significant: $F$ (3, $301)=52.65, p<.001, \eta^{2}=.34$ for the main effect of country of origin and $F(3,301)=3.52, p=.02, \eta^{2}=.03$ for the main effect of gender. The Box' $M$ test of equality of covariance matrices yielded a $p$-value of less than .001, but the outcome was disregarded because this test was notoriously known to be sensitive and the robustness of significance tests was expected when the sample sizes were approximately equal (Tabachnick \& Fidell, 2007). Pillai's trace, the pooled effect variances, was used instead of Wilks' lambda for multivariate statistical inference because of the advantage of Pillai's criterion in terms of robustness when there was more than one degree of freedom for effect.

Tests of between-subjects effects again failed to find any statistically significant effects of country of origin or gender on the use of SRL strategies: $F(1,303)=0.53, p=.47, \eta^{2}=.002$ for the main effect of country of origin and $F(1,303)=0.08, p=.77, \eta^{2}<.001$ for the main effect of gender. The main effect of country of origin, however, was significant for the ratings of self-efficacy beliefs, $F(1,303)=56.33, p<.001, \eta^{2}=.22$. The main effect of gender was also significant on the ratings of self-efficacy beliefs, $F(1,303)=5.50, p=.02, \eta^{2}=.02$. Female students $(M=5.11, S D=1.00)$ reported significantly stronger self-efficacy beliefs than male students $(M$ $=4.86, S D=0.88)$. As for the outcome of English language test scores, the main effect of county of origin was not significant, $F(1,303)=2.39, p=.12, \eta^{2}=.008$. The English language test scores of Chinese students $(M=$ $66.70, S D=8.49)$ and German students $(M=61.99, S D=14.32)$ were not statistically significantly different. The main effect of gender, however, was significant, $F(1,303)=6.53, p=.47, \eta^{2}=.02$. Male students $(M=$ $67.50, S D=7.71)$ achieved significantly higher scores than female students $(M=62.36, S D=13.42)$ in English language tests regardless of their country of origin.

As for the subconstructs of QESRLS, German students $(M=2.42, S D=0.44)$ used more self-evaluation strategies than Chinese students $(M=1.91, S D=0.61), F(1,357)=81.10, p<.001, \eta^{2}=.19$. German students $(M=2.50, S D=0.43)$ used more persistence strategies than Chinese students $(M=2.22, S D=0.60), F(1,357)$ $=24.35, p<.001, \eta^{2}=.06$. German students $(M=1.63, S D=0.59)$ used more seeking opportunity strategies than Chinese students $(M=1.42, S D=0.60), F(1,357)=12.17, p=.001, \eta^{2}=.03$. On the other hand, Chinese students $(M=1.75, S D=0.51)$ used more organizing and transforming strategies than German students $(M=$ $1.44, S D=0.36), F(1,357)=42.04, p<.001, \eta^{2}=.11$. Chinese students $(M=1.65, S D=0.55)$ used more rehearsing and memorizing strategies than German students $(M=1.01, S D=0.50), F(1,357)=125.90, p<.001$, $\eta^{2}=.26$. Chinese students $(M=1.89, S D=0.70)$ used more self-consequence strategies than German students $(M=1.59, S D=0.63), F(1,357)=18.35, p<.001, \eta^{2}=.05$. Chinese students $(M=1.69, S D=0.70)$ used more goal-setting strategies than German students $(M=1.31, S D=0.61), F(1,357)=29.65, p<.001, \eta^{2}=.08$. Finally, Chinese students $(M=1.74, S D=0.58)$ used more using native language strategies than German students $(M=1.45, S D=0.65), F(1,357)=20.79, p<.001, \eta^{2}=.06$. There is no statistically significant difference between Chinese and German students on the use of seeking social assistance, taking records, or interpretive guessing strategies $(p>.05)$.

The path diagrams of the structural model for the relationships between self-efficacy, use of SRL strategies, and English language test scores were presented in Figure 3, for Chinese and German students, respectively. 


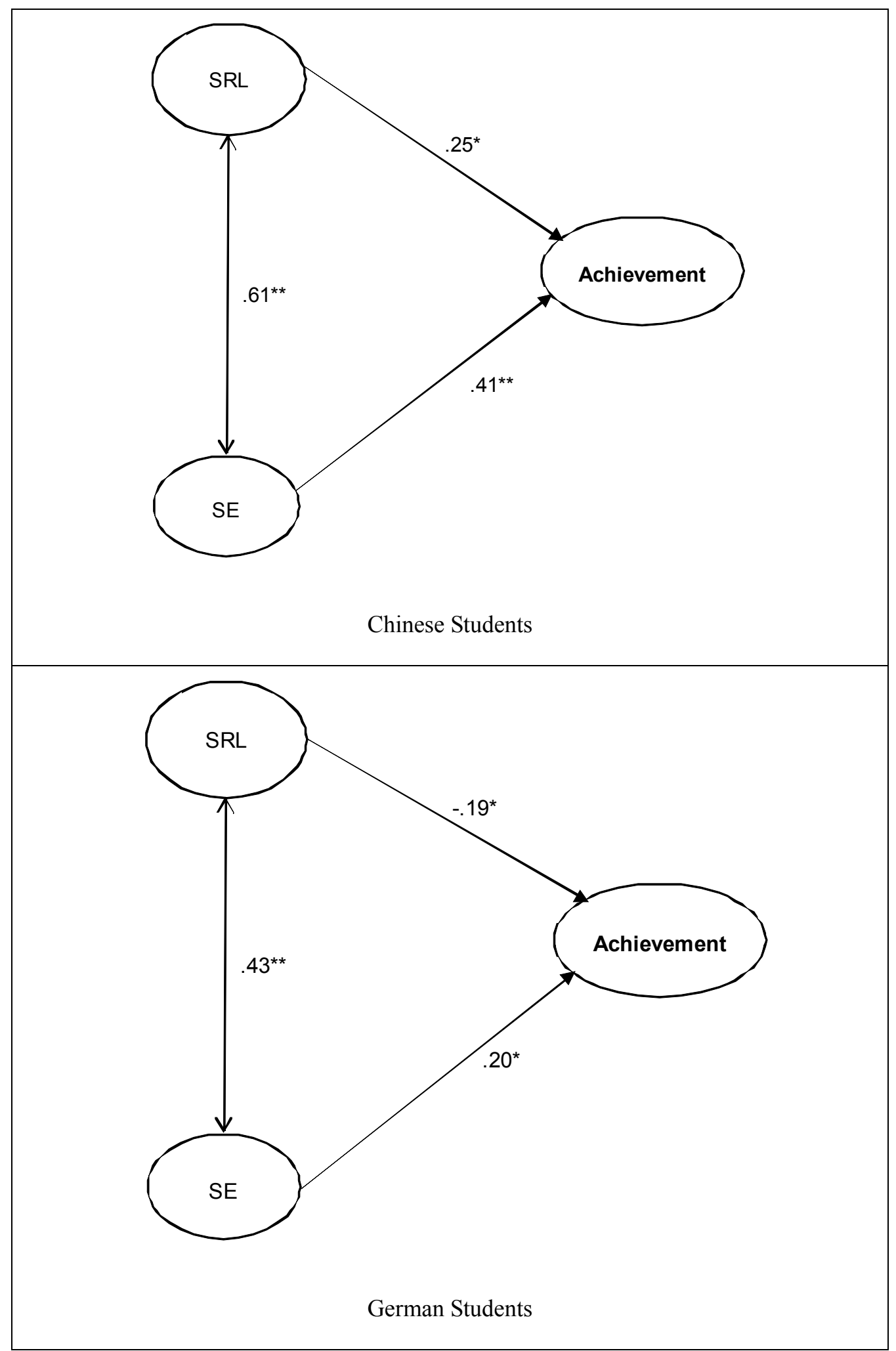

Figure 3. Path diagram of the structural model for the relationships between self-efficacy, self-regulation, and achievement in English language $(* p<.05 ; * * p .01)$

An interesting result from Figure 3 is that the relationship between use of SRL strategies and English language test scores was positive for Chinese students but negative for German students. Statistically significantly positive relationships were found between self-efficacy and use of SRL strategies with both Chinese and German students. 
Similar results were noted for the relationship between self-efficacy and achievement.

When participants were split into two groups by the dummy variable "passage", another interesting result emerged: nearly half of the Chinese students $(n=92)$ reported reading the passage first, but only $25 \%$ of the German students $(n=39)$ were in this category. Most of the German students $(n=119)$ and the other half of Chinese students $(n=108)$ reported reading the questions first before reading the passage while working on a reading comprehension exam. The distribution of these two groups of students in each country was statistically significant, $\chi^{2}(d f=1)=17.29, p<.001$. Three-way interaction effect between country of origin, gender, and passage on the combination of self-efficacy beliefs and English language test scores was not statistically significantly different from zero, $F(2,298)=0.77, p=.46, \eta^{2}=.005$. The two-way interaction effect between country of origin and gender was not statistically significant either, $F(2,298)=0.01, p=.99, \eta^{2}<.001$. The two-way interaction effect between county of origin and passage, however, was statistically significant: $F(2,298)$ $=3.09, p=.047, \eta^{2}=.02$. The two-way interaction effect between gender and passage was also statistically significant: $F(2,298)=3.91, p=.02, \eta^{2}=.03$. Tests of between-subjects effects revealed that the two-way interaction effect between country of origin and passage was only significant on self-efficacy beliefs, $F(1,299)$ $=3.90, p=.049, \eta^{2}=.01$. Similarly, the two-way interaction effect between gender and passage was only significant on English language test scores, $F(1,299)=6.13, p=.01, \eta^{2}=.02$. As a result, ANOVA was conducted for each country for the outcome of self-efficacy and for each gender for the outcome of English language test scores.

For German students, those who read the passage first $(M=5.83, S D=0.63)$ reported stronger self-efficacy beliefs than those who read the questions first $(M=5.53, S D=0.71), F(1,156)=5.38, p=.02, \eta^{2}=.03$. For Chinese students, however, there was no statistically significant difference between those who read the passage first $(M=4.58, S D=0.87)$ and those who read the questions first $(M=4.69, S D=0.88)$ with respect to their self-report of self-efficacy beliefs, $F(1,198)=0.78, p=.38, \eta^{2}=.004$.

For female students, there was no statistically significant difference between those who read the passage first ( $M$ $=67.12, S D=8.55)$ and those who read the questions first $(M=67.85, S D=6.88)$ with respect to their English language test scores, $F(1,159)=0.36, p=.55, \eta^{2}=.002$. For male students, however, those who read the passage first $(M=66.45, S D=13.02)$ gained statistically significantly higher scores on English language test than those who read the questions first $(M=60.65, S D=13.27), F(1,144)=5.86, p=.02, \eta^{2}=.04$.

\section{Discussions and Implications}

This study not only provided further evidence of validity information about QESE used to measure student self-efficacy beliefs in learning English as a foreign language, but also established factorial invariance of QESE between Chinese and German college students. The statistically significant relationships between self-efficacy beliefs, use of SRL strategies, and English language test scores extended the findings related to these constructs to the field of studying English as a foreign language from previous studies in first language English reading and writing as well as in mathematics education (Boekaerts \& Cascallar, 2006; Pajares \& Valiante, 2002; Pape \& Wang, 2003; Zimmerman \& Cleary, 2006; Zimmerman \& Martinez-Pons, 1990).

Chinese students reported significantly lower levels of self-efficacy beliefs than German students in total self-efficacy scores and each of the four subscale scores in listening, speaking, reading, and writing. These findings support previous cross-cultural studies that claimed Chinese students were more likely to report lower levels of self-efficacy beliefs in comparison to European and American students (Earley, 1999; Eaton \& Dembo, 1997; Salili et al., 2001; Scholz et al., 2002; Schwarzer \& Born, 1997) and extended the results to the domain of learning English as a foreign language.

What is surprising in this study, though, is that female students were more efficacious than male students but gained significantly lower scores on English language test regardless of their countries of origin. Previous studies reported that female students were more motivated to study a foreign language and were more likely to choose to study a foreign language than male students (Bacon \& Finnemann, 1992). As women's self-efficacy beliefs were more likely to be influenced by social persuasions and vicarious experiences (Zeldin, Britner, \& Pajares, 2008), we expected female participants in this study to be more efficacious than male students. Although we speculated that our self-efficacy survey focuses on communication skills whereas the English language test focuses on grammar and syntax and our study is limited in that we have a relatively small sample of male students (about 25\%), the contradictory result of these participants' self-efficacy beliefs with their English language test scores is worthy of further investigations.

The relationship between the use of SRL strategies and English language test scores was positive for Chinese students but negative for German students. This is also surprising because a positive relationship was expected 
based upon findings from previous research (Ainley \& Patrick, 2006; Pape \& Wang, 2003; Shih \& Alexander, 2000; Zimmerman \& Cleary, 2006). One interpretation is that QESRLS, developed with Chinese students, might not be a good measure of the use of SRL strategies for German students potentially due to differences in cultural, linguistic, and social context. Another interpretation is that German students do use different SRL strategies in learning English in comparison to Chinese students. This interpretation was confirmed with our findings that German students favor some particular SRL strategies while Chinese students favor some other SRL strategies. This could also be due to the differences in instructional method in German and Chinese classrooms as SRL strategies are process-based and vary according to context, domain, and classroom environment (Boekaerts \& Cascallar, 2006). Future studies should develop a unique measure of SRL strategies that reflects contextual factors in German culture for German students.

Although no significant differences were found with respect to English language test scores between Chinese and German students and between students who read the passage first and students who read the questions first when taking English reading comprehension exams in general, differences within each country and for each gender were found. In China, students who read the passage first and those who read the questions first were not significantly different in their self-report of self-efficacy beliefs. In Germany, however, students who read the passage first were more efficacious than those who read the questions first. Male students who read the passage first had significantly better achievement than male students who read the questions first in English language test. This finding was not found with female students. These findings should be interpreted with caution because the distribution of male and female students in the Chinese sample and the German sample was not the same and the sample is quite unbalanced in gender (only about $25 \%$ of the participants were male students). Although we are not certain if this could be a reason for the unexpected results, further studies should consider using a more balanced sample between two countries. Also, the English language tests used with the German sample and the Chinese sample are not the same. The results would be more convincing and more generalizable if the same English language test could be administered in both countries.

Implications of the findings to foreign language teaching and learning in China may include teachers advising and encouraging the use and application of SRL strategies to students' English learning. These strategies include those that were reportedly less used by Chinese students in the present study, such as self-evaluation, persisting, seeking opportunity, and reviewing records strategy. In particular, teachers may especially advise male students to adopt the strategy of reading a passage first before reading the questions to generate answers for a reading comprehension test. In addition, although Chinese students reported significantly lower self-efficacy beliefs than German students, the outcomes of English language test scores were no different between the two groups. This suggests that for Chinese students, perceived self-efficacy may not be a suitable predictor of academic performance in relation to the academic achievement of its European and American counterparts. Instead, factors in the cultural and societal context should be considered, such as levels of self-expectation, attributions, parental expectation, fear of failure, and social values that may play more weights in the levels of academic performance of Chinese students.

\section{References}

Ainley, M., \& Patrick, L. (2006). Measuring self-regulated learning processes through tracking patterns of student interaction with achievement activities. Educational Psychology Review, 18, 267-286. http://dx.doi.org/10.1007/s10648-006-9018-z

Al-Harthi, A. S. (2010). Learner self-regulation in distance education: A cross-cultural study. The American Journal of Distance Education, 24, 135-150. http://dx.doi.org/10.1080/08923647.2010.498232

Bacon, S. M., \& Finnemann, M. D. (1992). Sex differences in self-reported beliefs about foreign-language learning and authentic oral and written input. Language Learning, 42, 471-495. http://dx.doi.org/10.1111/j.1467-1770.1992.tb01041.x

Bajka, B. (2009). Open doors 2009: Report on international educational exchange. New York, NY: Institue of International Education, Inc.

Bandura, A. (1997). Self-efficacy: The exercise of control. New York: W. H. Freeman and Company.

Bandura, A. (2006). Guide for constructing self-efficacy scales. In F. Pajares, \& T. Urdan (Eds.), Self-efficacy beliefs of adolescents (pp. 307-337). Greenwich, CT: Information Age Publishing.

Barker, J. R., \& Olsen, J. P. (1995). Medical students' learning strategies: Evaluation of first-year changes. Journal of Educational Psychology, 80, 321-331.

Boekaerts, M., \& Cascallar, E. (2006). How far have we moved toward the integration of theory and practice in 
self-regulation? Educational Psychology Review, 18, 199-210. http://dx.doi.org/10.1007/s10648-006-9013-4

Bong, M. (2002). Predictive utility of subject-, task-, and problem-specific self-efficacy judgments for immediate and delayed academic performances. Journal of Experimental Education, 70, 133-162. http://dx.doi.org/10.2307/20152673

Bong, M. (2006). Asking the right question: How confident are you that you could successfully perform these tasks? In F. Pajares, \& T. Urdan (Eds.), Self-efficacy beliefs of adolescents (pp. 287-305). Greenwich, CT: Information Age Publishing.

Bong, M., \& Clark, R. E. (1999). Comparison between self-concept and self-efficacy in academic motivation research. Educational Psychologist, 34, 139-153.

Brislin, R. W. (1970). Back-translation for cross-cultural research. Journal of Cross-Cultural Psychology, 1(3), 185-216. http://dx.doi.org/ 10.1177/135910457000100301

Byrne, B. M. (1996). Measuring self-concept across the life span: Issues and instrumentation. Washington, DC: American Psychological Association.

Cheung, G. W., \& Rensvold, R. B. (2002). Evaluating goodness-of-fit indexes for testing measurement invariance. Structural Equation Modeling, 9, 233-255. http://dx.doi.org/10.1207/S15328007SEM0902_5

Damon, W., \& Hart, D. (1982). The development of self-understanding from infancy through adolescence. Child Development, 53, 841-864. http://dx.doi.org/10.1111/1467-8624.ep8587555

Earley, P. C. (1999). Playing follow the leader: Status-determining traits in relation to collective efficacy across

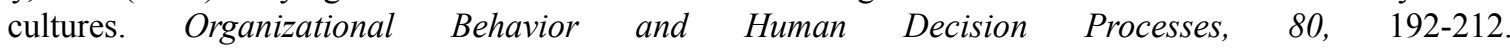
http://dx.doi.org/10.1006/obhd.1999.2863

Eaton, M. J., \& Demo, M. H. (1997). Differences in the motivation beliefs of Asian American and non-Asian students. Journal of Educational Psychology, 89, 433-440. http://dx.doi.org/10.1037/0022-0663.89.3.433

Fan, X., \& Sivo, S. A. (2005). Sensitivity of fit indices to misspecified structural or measurement model components: Rationale of two-index strategy revisited. Structural Equation Modeling, 12, 343-367. http://dx.doi.org/10.1207/s15328007sem1203_1

Green, J. M., \& Oxford, R. (1995). A closer look at learning strategies, L2 proficiency, and gender. TESOL Quarterly, 29, 261-297. http://dx.doi.org/10.2307/3587625

Hsiao, T. Y., \& Oxford, R. L. (2002). Comparing theories of language learning strategies: A confirmatory factor analysis. The Modern Language Journal, 2, 368-383. http://dx.doi.org/10.2307/1192849

Hu, L., \& Bentler, P. M. (1999). Cutoff criteria for fit indexes in covariance structure analysis: Conventional criteria versus new alternatives. Structural Equation Modeling, 6, 1-55. http://dx.doi.org/10.1080/10705519909540118

Huang, S. C., Lloyd, P., \& Mikulecky, L. (1999). ESL literacy self-efficacy: Developing a new scale. Retrieved from ERIC (Document Reproduction Service No. ED 427541).

Jöreskog, K. G., \& Sörbom, D. (2006). LISREL 8.8 for Windows [Computer Software]. Lincolnwood, IL: Scientific Software International, Inc.

Klassen, R. M. (2004). Optimism and realism: A review of self-efficacy from a cross-cultural perspective. International Journal of Psychology, 39, 205-230. http://dx.doi.org/10.1080/00207590344000330

Klassen, R. M., Ang, R. P., Chong, W. H., Krawchuk, L. L., Huan, V. S., Wong, I. Y. F., \& Yeo, L. S. (2009). A cross-cultural study of adolescent procrastination. Journal of Research on Adolescence, 19, 799-811. http://dx.doi.org/10.1111/j.1532-7795.2009.00620.x

Luszczynska, A., Gutierrez-Dona, B., \& Schwarzer, R. (2005). General self-efficacy in various domains of human functioning: Evidence from five countries. International Journal of Psychology, 40, 80-89. http://dx.doi.org/10.1080/00207590444000041

Luszczynska, A., Scholz, U., \& Schwarzer, R. (2005). The general self-efficacy scale: Multicultural validation studies. The Journal of Psychology, 139, 439-457. http://dx.doi.org/10.3200/JRLP.139.5.439-457

Mantel, N., \& Haenszel, W. (1959). Statistical aspects of the analysis of data from retrospective studies of disease. Journal of National Cancer Institute, 22, 719-748.

Marsh, H. W. (1992). Content specificity of relations between academic achievement and academic self-concept. 
Journal of Educational Psychology, 84, 35-42. http://dx.doi.org/10.1037/0022-0663.84.1.35

Marsh, H. W., Byrne, B. M., \& Shavelson, R. J. (1988). A multifaceted academic self-concept: Its hierarchical structure and its relation to academic achievement. Journal of Educational Psychology, 80, 366-380. http://dx.doi.org/10.1037/0022-0663.80.3.366

Marsh, H. W., Hau, K. T., \& Wen, Z. (2004). In search of golden rules: Comment on hypothesis-testing approaches to setting cutoff values for fit indexes and dangers in overgeneralizing Hu and Bentler's (1999) findings. Structural Equation Modeling, 11, 320-341. http://dx.doi.org/10.1207/s15328007sem1103_2

Nguyen, P.-M., Terlouw, C., \& Pilot, A. (2006). Culturally appropriate pedagogy: The case of group learning in a Confucian heritage culture context. Intercultural Education, 17, 1-19. http://dx.doi.org/10.1080/14675980500502172

Nisbet, D. L., Tindall, E. R., \& Arroyo, A. A. (2005). Language learning strategies and English proficiency of Chinese university students. Foreign Language Annals, 38, 100-107. http://dx.doi.org/10.1111/j.1944-9720.2005.tb02457.x

Oxford R. (1990). Language learning strategies: What every teacher should know. Boston, MA: Heinle \& Heinle Publishers.

Oxford, R. (1996). Language learning strategies around the world: Cross-cultural perspectives. Second Language Teaching and Curriculum Center, University of Hawaii Press, Honolulu, HI.

Oxford R. (2011). Teaching and researching language learning strategies. New York, NY: Pearson.

Oxford, R., \& Burry-Stock, J. A. (1995). Assessing the use of language learning strategies worldwide with the ESL/EFL version of the strategy inventory for language learning (SILL). System, 23, 1-23. http://dx.doi.org/10.1016/0346-251X(94)00047-A

Pajares, F. (1996). Self-efficacy beliefs in academic settings. Review of Educational Research, 66, 543-578. http://dx.doi.org/10.3102/00346543066004543

Pajares, F., \& Valiante, G. (2002). Students' self-efficacy in their self-regulated learning strategies: A developmental perspective. Psychologia, 45, 211-221. http://dx.doi.org/10.2117/psysoc.2002.211

Pape, S. J., \& Wang, C. (2003). Middle school children's strategic behavior: Classification and relation to academic achievement and mathematical problem solving. Instructional Science, 31(6), 419-449. http://dx.doi.org/10.1023/A:1025710707285

Piers, E. V., \& Harris, D. B. (1964). Age and other correlates of self-concept in children. Journal of Educational Psychology, 55, 91-95. http://dx.doi.org/10.1037/h0044453

Pintrich, P. R. (2004). A conceptual framework for assessing motivation and self-regulated learning in college students. Educational Psychology Review, 16, 385-407. http://dx.doi.org/10.1007/s10648-004-0006-x

Pintrich, P. R., \& Schunk, D. H. (1996). Motivation in education: Theory, research and applications. Englewood Cliffs, NJ: Merrill Prentice-Hall.

Pintrich, P. R., Smith, D., Garcia, T., \& McKeachie, W. (1993). Predictive validity and reliability of the motivated 7strategies for learning questionnaire (MSLQ). Educational and Psychological Measurement, 53, 801-813. http://dx.doi.org/10.1177/0013164493053003024

Sachs, J., Law, Y. K., Chan, C. K. K., \& Rao, N. (2001). A nonparametric item analysis of the Motivated Strategies for Learning Questionnaire - Chinese version. Psychologia, 44, 197-208. http://dx.doi.org/10.2117/psysoc.2001.197

Salili, F., Chiu, C. Y., \& Lai, S. (2001). The influence of culture and context on students' motivational orientation and performance. In F. Salili, C. Y. Chiu, \& Y. Y. Hong (Eds.), Student motivation: The culture and context of learning (pp. 221-247). New York, NY: Kluwer.

Scholz, U., Gutierrez-Dona, B., Sud, S., \& Schwarzer, R. (2002). Is general self-efficacy a universal construct? Psychometirc findings from 25 countries. European Journal of Psychological Assessment, 18, 242-251. http://dx.doi.org/10.1027//1015-5759.18.3.242

Schunk, D. H. (1991). Self-efficacy and academic motivation. Educational Psychologist, 26, 207-231.

Schunk, D. H., \& Lilly, M. W. (1984). Sex differences in self-efficacy and attributions: Influence of performance feedback. Journal of Early Adolescence, 4, 203-213. http://dx.doi.org/10.1177/0272431684043004 
Schwarzer, R., BaBler, J., Kwiatek, P., Schroder, K., \& Zhang, J. X. (1997). The assessment of optimistic self-beliefs: Comparison of the German, Spanish, and Chinese versions of the general self-efficacy scale. $\begin{array}{lllll}\text { Applied Psychology: An } & \text { Review, } & 46, & \text { 69-88. }\end{array}$ http://dx.doi.org/10.1111/j.1464-0597.1997.tb01096.x

Schwarzer, R., \& Born, A. (1997). Optimistic self-beliefs: Assessment of general perceived self-efficacy in 13 countries. World Psychology, 3, 177-190.

Schwarzer, R., Born, A., Iwawaki, S., Lee, Y-M, Saito, E., \& Yue, X. (1997). The assessment of optimistic self-beliefs: Comparison of the Chinese, Indonesian, Japanese, and Korean versions of the general self-efficacy scale. Psychologia, 40, 1-13.

Shih, S., \& Alexander, J. M. (2000). Interacting effects of goal setting and self- or other-referenced feedback on children's development of self-efficacy and cognitive skill within the Taiwanese classroom. Journal of Educational Psychology, 92, 536-543. http://dx.doi.org/10.1037/0022-0663.92.3.536

Tabachnick, B. G., \& Fidell, L. S. (2007). Using multivariate statistics (5th ed.). New York: Pearson.

Turner, J. C. (2006). Measuring self-regulation: A focus on activity. Educational Psychology Review, 18, 293-296. http://dx.doi.org/10.1007/s10648-006-9022-3

Wang, C., Kim, D. H., Bong, M., \& Ahn, H. S. (in press). Examining measurement properties of an English self-efficacy scale for English language learners in Korea. International Journal of Educational Research.

Wang, C., Wang. L., \& Li, Y. (2007, March). Chinese secondary school self-regulated learners of English. Paper presented at TESOL (Teachers of English to Speakers of Other Languages) Convention, Seattle, WA.

Yan, W., \& Gaier, E. L. (1994). Causal attributions for college success and failure: An Asian-American comparison. Journal of Cross-Cultural Psychology, 25, 146-158. http://dx.doi.org/10.1177/0022022194251009

Zeldin, A., Britner, S., \& Pajares, F. (2008). A Comparative Study of Self-Efficacy Beliefs of Successful Men and Women in Mathematics, Science, and Technology Careers. Journal of Research in Science Teaching, 45, 1036-1058. http://dx.doi.org/10.1002/tea.20195

Zimmerman, B. J. (2000). Attaining self-regulation: A social cognitive perspective. In M. Boekaerts, P. R. Pintrich, \& M. Zeidner (Eds.), Handbook of Self-Regulation (pp. 13-39). San Diego, CA: Academic Press. http://dx.doi.org/10.1016/B978-012109890-2/50031-7

Zimmerman, B. J., \& Cleary, T. J. (2006). Adolescents' development of personal agency: The role of self-efficacy beliefs and self-regulatory skill. In F. Pajares, \& T. Urdan (Eds.), Self-efficacy beliefs of adolescents (pp. 45-69). Greenwich, CT: Information Age Publishing.

Zimmerman, B. J., \& Martinez-Pons, M. (1990). Student differences in self-regulated learning: Relating grade, sex, and giftedness to self-efficacy and strategy use. Journal of Educational Psychology, 82, 51-59.

\section{Appendix A: Questionnaire of English Self-Efficacy (English Equivalent of the German Version)}

\section{Listening Efficacy:}

Item 1: Can you understand stories told in English?

Item 3: Can you understand American English TV programs?

Item 9: Can you understand radio programs in English speaking countries?

Item 10: Can you understand English TV programs?

Item 15: If your teacher gives you an audio-recorded English dialogue about school life, can you understand it?

Item 22: Can you understand English movies without German subtitles?

Item 24: Can you understand English songs?

Item 27: Can you understand telephone numbers spoken in English?

\section{Speaking Efficacy:}

Item 4: Can you introduce your university in English? 
Item 6: Can you tell the directions to your classroom from your home/dormitory in English?

Item 8: Can you tell a story in English?

Item 17: Can you ask questions to your teachers in English?

Item 19: Can you introduce your English teacher in English?

Item 20: Can you discuss in English with your classmates some topics assuming all of you are interested?

Item 23: Can you answer your teachers' questions in English?

Item 30: Can you introduce yourself in English?

\section{Reading Efficacy:}

Item 2: Can you finish your homework of English reading independently?

Item 12: When you read English articles, can you guess the meaning of unknown words?

Item 16: Can you understand the English news on the Internet?

Item 21: Can you read English short novels?

Item 25: Can you read English newspapers?

Item 26: Can you find the meaning of new words by using English-English dictionaries?

Item 29: Can you understand English articles about German culture?

Item 32: Can you understand new reading materials (e.g., news from the Time magazine) selected by your instructor?

\section{Writing Efficacy:}

Item 5: If you have access to internet, can you release news on the Internet (e.g., facebook, twitter, blogs)?

Item 7: Can you write English compositions assigned by your teachers?

Item 11: Can you leave a message to your classmates in English?

Item 13: Can you make new sentences with the words just learned?

Item 14: Can you send emails in English?

Item 18: Can you make sentences with English idiomatic phrases?

Item 28: Can you write diaries in English?

Item 31: Can you write an article in about two pages about your English teacher in English?

\section{Appendix B: Questionnaire of English Self-Regulated Learning Strategies}

(English Equivalent of the German Version)

\section{Self-Evaluation Strategies}

Item 8: Check my English homework before turning it in.

Item 30: Proofread my English compositions when I complete writing.

Item 58: Adjust my reading speed according to the difficulty of the article.

Item 65: When I finish my English composition, I have a rest and then read it again to check whether it should be revised.

\section{Organizing and Transforming Strategies}

Item 2: Write an outline before writing English compositions.

Item 13: Write an outline after reading an English article.

Item 16: Summarize the main idea of each paragraph when reading.

Item 18: Summarize the most important points of the whole English article after I read it.

Item 21: Pay attention to the English language structure during reading. 
Item 26: Classify new words in order to memorize them.

Item 32: When I listen to English, I pay attention to the stressed words or phrases in order to comprehend the sentence.

Item 34: Use the title of an English article to help understand that article.

Item 37: When I read an English article, I imagine the scene described in the article in order to memorize what I have read.

Item 38: Make a chart to summarize the grammatical points learned.

Item 40: Recite similar words all together to distinguish slight differences.

Item 44: Memorize English words whose pronunciations are similar.

Item 45: Memorize a new word by memorizing where I learn it.

Item 50: Memorize meanings of words by using prefixes and suffixes.

Item 57: Pay attention to the beginning and end of each paragraph in my English reading.

Item 60: Underline key points during my English reading.

Item 63: Make sure to write a topic sentence in each paragraph in writing.

Item 64: Make sure that the content of each paragraph supports its topic sentence in English writing.

\section{Rehearsing and Memorizing Strategies}

Item 14: Recite English texts in the process of studying English.

Item 22: Review flash cards of new words in order to memorize them.

Item 24: Read texts I have learned several times in order to recite them from memory.

Item 28: Write new words many times in order to memorize the spellings.

Item 43: Read new words repeatedly in order to memorize them.

\section{Seeking Social Assistance Strategies}

Item 6: Consult teachers when I encounter difficulties in the process of studying English.

Item 12: Search related documents when I have difficulties in the process of studying English.

Item 19: Ask classmates when I have questions in my English study.

\section{Persistence Strategies}

Item 5: Keep reading when I encounter difficulties in English reading.

Item 9: Read an English article several times if I don't understand it at the first time.

Item 20: Listen to tape-recorded English several times if I cannot understand it for the first time.

\section{Seeking Opportunity Strategies}

Item 23: Listen to American or British radio broadcasts to improve my pronunciation.

Item 29: Use sentence patterns just learned to make new sentences for practice.

Item 39: Send emails to friends in English on my initiative.

Item 46: Try my best to find opportunities to practice my oral English.

Item 48: Watch English TV programs on my initiative.

Item 52: Listen to English radio programs on my initiative.

Item 54: Try to use various English expressions to express the same meaning.

Item 66: Use words just learned to make new sentences on my initiative. 


\section{Taking Records Strategies}

Item 1: Write down the mistakes I often make in the process of studying English.

Item 4: Take notes in English classes.

\section{Self-Consequence Strategies}

Item 15: Reward myself when I make progress in studying English.

Item 53: Have a break when I am tired during my English study.

\section{Goal-Setting Strategies}

Item 10: Make a study plan in the process of studying English.

Item 11: Set a goal to study English.

\section{Reviewing Records Strategies}

Item 3: Reread the English texts I have read in class.

Item 51: Review my notes of English class before examinations

\section{Use of Native Language Strategies}

Item 33: Use phrases in German which are similar to English words in pronunciation to memorize the English words.

Item 41: Compare the similarities and differences between English and German.

Item 47: Consider how to say something in English in my mind before saying it out loud.

Item 49: When I listen to English, I translate it into German to help me understand it.

Item 55: Translate what I have read in English into my home language to help me understand it.

Item 67: Think out a composition in German before writing it in English.

\section{Interpretative Guess strategies}

Item 25: Guess the meaning of new words by considering the contexts.

Item 27: Guess what people mean by reading their expressions and movements when watching an English movie.

Item 31: When I come across a new word which doesn't hinder my comprehension, I skip it.

Item 35: When somebody speaks English, I guess what he/she will say according to what he/she has said already. Item 59: Use my background knowledge to comprehend English articles. 